\section{Commentary: Nature versus nurture in unicuspid aortic valve aortopathy}

\author{
Amine Mazine, MD, Malak Elbatarny, MD, and \\ Maral Ouzounian, MD, PhD
}

Individuals with congenital aortic valve malformations are at a significantly higher risk of developing ascending aortic aneurysm and dissection than individuals with tricuspid aortic valves (TAV). ${ }^{1,2}$ Whether or not this association is primarily driven by genetic or hemodynamic factors is a long-standing question in the field. Most studies have focused on patients with bicuspid aortic valve (BAV). In contrast, a paucity of data exist on the rarer clinical entity of unicuspid aortic valve (UAV). As such, the study by Balint and colleagues ${ }^{3}$ is a welcome addition to the current body of literature on this topic. The authors examined the messenger RNA (mRNA) and protein expression levels of endothelial nitric oxide synthase (eNOS) in aortic tissue obtained from patients who underwent cardiac surgery. Their goal was to compare the expression pattern of this marker between patients with TAV and those with UAV. This was motivated by the previously documented observation that the expression of this eNOS is altered in patients with BAV, and a fortiori in those with BAV aortopathy. ${ }^{4}$ The authors were interested in comparing expression levels in dilated versus nondilated aortas, as well as regional differences in eNOS expression between segments of aorta presumed to be exposed to different hemodynamic flow patterns. To

\footnotetext{
From the Division of Cardiovascular Surgery, Peter Munk Cardiac Centre, Toronto General Hospital and the University of Toronto, Toronto, Ontario, Canada. Disclosures: The authors reported no conflicts of interest.

The Journal policy requires editors and reviewers to disclose conflicts of interest and to decline handling or reviewing manuscripts for which they may have a conflict of interest. The editors and reviewers of this article have no conflicts of interest.

Received for publication Oct 25, 2021; revisions received Oct 25, 2021; accepted for publication Oct 29, 2021; available ahead of print Nov 24, 2021.

Address for reprints: Maral Ouzounian, MD, PhD, Division of Cardiovascular Surgery, Peter Munk Cardiac Centre, Toronto General Hospital, 200 Elizabeth St, 4N-464, Toronto, Ontario M5G 2C4, Canada (E-mail: maral.ouzounian@uhn.ca). JTCVS Open 2021;8:170-1

2666-2736

Copyright (C) 2021 The Author(s). Published by Elsevier Inc. on behalf of The American Association for Thoracic Surgery. This is an open access article under the CC BY-NC-ND license (http://creativecommons.org/licenses/by-nc-nd/4.0/).

https://doi.org/10.1016/j.xjon.2021.10.058
}

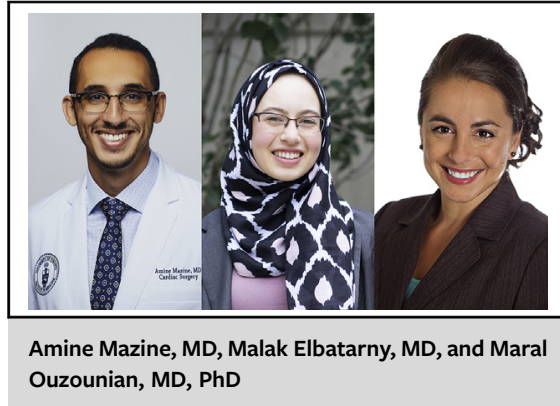

CENTRAL MESSAGE

Expression levels of endothelial nitric oxide synthase are altered in patients with unicuspid aortic valve.

achieve this, they collected samples from the concavity and convexity of the ascending aorta and analyzed them separately. The authors found that eNOS protein concentrations-but not their mRNA expression-were lower in nondilated aortic samples from UAV patients compared with TAV patients. In contrast, when comparing aneurysmal aortas, no difference was found in eNOS mRNA or protein expression between dilated TAV and UAV aortas. Finally, the authors show that in patients with UAV, eNOS expression is similar across the concavity and convexity of the ascending aorta, leading them to conclude that alterations in eNOS expression are "independent of alterations in aortic wall shear stress" and "likely caused by a congenital defect in eNOS signaling that is stronger than turbulence-induced expression patterns." 3

Although this study raises some interesting questions, the aforementioned conclusions are somewhat overstated in light of some significant study design limitations. The multiplicity of factors considered (valve morphology, presence/absence of dilation, and concavity vs convexity), combined with the relatively small sample size, make this study at high risk for a type 1 error. As such, these results should be interpreted with caution and considered hypothesis-generating at best. Furthermore, in the absence of 4-dimensional magnetic resonance imaging flow data, the assumption that concave versus convex segments of the ascending aorta are exposed to different hemodynamic flow patterns is speculative. This is especially true in the setting of UAV, where the 
presence and direction of flow jets across the aortic valve can significantly influence flow dynamics in the ascending aorta.

Beyond these methodological considerations, the molecular processes involved in UAV-related aortopathy are likely complex and multifactorial, such that the examination of a single marker is unlikely to yield the full picture. Thankfully, in recent years, the emergence of sophisticated multiomics analysis methods ${ }^{5}$ has provided a powerful platform to address questions like the one raised by Balint and colleagues. ${ }^{3}$

\section{References}

1. Michelena HI, Khanna AD, Mahoney D, Margaryan E, Topilsky Y, Suri RM, et al Incidence of aortic complications in patients with bicuspid aortic valves. JAMA 2011;306:1104-12.

2. Slostad BD, Witt CM, O'Leary PW, Maleszewski JJ, Scott CG, Dearani JA, et al Unicuspid aortic valve: demographics, comorbidities, echocardiographic features, and long-term outcomes. Circulation. 2019;140:1853-5.

3. Balint B, Kollman C, Gauer S, Federspiel JM, Schäfers HJ. Endothelial nitric oxide synthase alterations are independent of turbulence in the aorta of patients with a unicuspid aortic valve. J Thorac Cardiovasc Surg Open. 2021;8:157-69.

4. Aicher D, Urbich C, Zeiher A, Dimmeler S, Schafers HJ. Endothelial nitric oxide synthase in bicuspid aortic valve disease. Ann Thorac Surg. 2007;83:1290-4.

5. Blaser MC, Kraler S, Luscher TF, Aikawa E. Multi-omics approaches to define calcific aortic valve disease pathogenesis. Circ Res. 2021;128:1371-97. 